\title{
Preparation and Evaluation of Pan Bread Made with Wheat flour and Psyllium Seeds for Obese Patients
}

\author{
El-Hadidy G. S.
}

Bread and Pasta. Dep., Food Tech. Res. Inst., Agric. Res. Center, Egypt. Received: 15 April 2020 / Accepted 16 June 2020 / Publication date: 30 June 2020

\begin{abstract}
In this covenant of functional foods, the world seeks for new healthier food products with appropriate proportions of bioactive constituents such as fiber, mineral elements, amino acids and phenols. The psyllium seed has good nutritional and pharmaceutical properties; therefore, its incorporation in pan bread could be beneficial in improving human health. In the current study, partial substitution of wheat flour (WF) with psyllium seed flour (PSF) at levels of 5\%,10\% and $15 \%$ were carried out to investigate the rheology properties of dough, baking performance, proximate compositions and physical properties of the pan bread. Partial substitution of WF with PSF increased the water absorption, arrival time and developing time of dough $(\mathrm{P} \leq 0.05)$, while, the dough extensibility was reduced. Also, elasticity and energy were increased by addition of PSF. Pan bread supplemented with PSF resulted in a reduction in quality in terms of specific loaf volume, while, weight was increased. PSF up to $15 \%$ could partially replace WF in pan bread; increase its nutritional value in terms of fiber, amino acids content and minerals, with only a small depreciation in the bread quality. Sensory evaluation showed that pan bread supplemented up to $15 \%$ PSF were acceptable to the panelists and there was significant difference in terms of appearance, crumb texture, crumb grain, crust color, taste, odor and overall acceptability compared to the control. The incorporation of PSF increased the minerals contents, amino acids contents and nutritional properties compared to the control (for pan bread).
\end{abstract}

Keywords: psyllium, obese, pan bread, amino acids, rheology

\section{Introduction}

Obesity causes many complications including dyslipidemia, diabetes, hypertension, and heart disease. Recently, obesity has also been associated with the increased incidence of many cancers Huang and Chen (2009), Dyslipidemia is a pathological disorder, and current evidence has highlighted not only total cholesterol but also triacylglycerol (TAG) as lipid risk factors in metabolic syndrome. Recently, community awareness in nutrition as a cornerstone for healthy life style has increased. Functional food is a concept of nutrition, based on the role of reducing the risk of disease. A food will be considered as a functional food if it gives one or more benefits or positive effects to the body beyond adequate nutritional effects in a way that is relevant to either improve the stage of health and wellbeing and/or reduce the risk of disease (Roberfroid, 2000). Wheat (Triticum aestivum) is a major of the important edible grains around the world (Alu'datt, 2012). It is used in many forms comprises flat or pan style leavened bread. Wheat flour is that it is depression in essential amino acids, such as lysine and methionine, which minimizes its nutritional value when utilization in foods products (Newman and Newman, 2006).

Plantago ovata, the common name of the psyllium that described as a short-stemmed annual herb, which grows between $(30-40 \mathrm{~cm})$, many of flowering shoots arise from the base of the plant (Jat et al., 2015). Psyllium has been recorded in many countries around the world since ancient times, and its use in India until $1500 \mathrm{BC}$ as medicine, as the Chinese used it as traditional medicine thousands of years ago.

Both Chinese and Indians used herb seeds to remediate of diarrhea, bladder problems constipation, high blood pressure and hemorrhoids, in North Americans and Europeans started using it as cholesterol and hyperglycemia treatment (Ashwini et al., 2014). Psyllium used in instant juices, ice cream, breakfast cereals and in bakery products similar cakes, biscuits, breads and muffins with varying functional and health aspects (Ziai et al., 2005).

Corresponding Author: El-Hadidy G. S., Bread and Pasta. Dep., Food Tech. Res. Inst., Agric. Res. Center, Egypt. E-mail: gamalelhadidy1982@gmail.com 
Plantago ovata mucilage has an extended history as a nutritive supplement due to its considerable amount of insoluble and soluble fiber being reported as a medicinally active gel forming natural polysaccharide, successfully used for the cure of diabetes, high cholesterol, obesity in kids, remediation of diarrhea, constipation, ulcerative colitis and inflammation bowel diseases (Singh, 2007). While, it's functional benefits, there are few reports about the combination of Psyllium in manufacturing foodstuffs Bedard et al., (1995) in developed countries Psyllium seed intake mainly results from the intake of capsules and other dietary preparations. Psyllium is world-famous as a laxative, is a potential source of nutritional supplement and has important biological antioxidant and anti-inflammatory properties (Samuelsen, 2000 and Beara et al., 2009). Plantago ovata seeds contain in $65 \%$ insoluble polysaccharides (lignin, cellulose and hemicellulose) and $35 \%$ of soluble fibers. The seeds comprise xylose, arabinose, rhamnose and galactose. Also, they verified that the polysaccharide of Plantago ovata husks can be used as a disintegrating agent in the development of fast-dissolving tablets (Pawar and Varkhade, 2014). The presence of mucilage's is on the level of 20-25\% Olivier, (2000). Plantago ovata psyllium is a source of natural and concentrated soluble fiber derived from psyllium husks. The husk is the represents the epidermal layer of the seeds, which is removed in a mechanical method. The total recovery of the husk is about $25-26 \%$ of the seeds. The husk comprises $4.07 \%$ ash, $6.83 \%$ fiber, $0.94 \%$ protein and $84.98 \%$ of total carbohydrates (Guo et al., 2008). It was verified Sukhija et al. (2016) that the psyllium hydrocolloid has a great potential to be used in the manufacture of edible films with interesting characterizes, that is, low water vapor permeability and high elasticity, elongation and a hydrophobic surface and solubility in water.

Bread is a staple food that closely related to people's daily life. It consists of flour, leavening agents and water. It is popular around the world and one of the oldest foods. Bread is usually known as important source of carbohydrates in the food pyramid to ensure that a person can get enough nutrition that needed by the body (Sivam et al., 2010). To produce healthy bread, bakers often reduce calories, fat and sugar, while increase fiber or water. Also, natural ingredients are seeking to substitute chemically produced ones.

Rheology properties of several fluids are suitable technologically to recognize the most suitable dough system design as well as optimize operating circumstances (El Sheikh, 2014). Brabender farinograph parameters has been successfully used as a sensitive tool for the investigate of characterization of bread dough properties; especially for the modifications caused by fiber at the period of mixing and developing of bread dough. Whereas, Brabender extensograph parameters permits indirect examination of the extension behavior of the dough at furthermore steps of bread manufacture (Koletta et al., 2014). The aim of the present study was to investigate the effect of partial substitution of wheat flour with psyllium seeds flour on the dough properties and pan bread making, and estimation of its proximate composition, bread quality, sensorial and physical properties.

\section{Materials and Methods}

\section{Materials}

Materials psyllium seed, wheat flour and other materials that used to produce pan bread such as fresh egg, instant active dry yeast, salt (sodium chloride) and shortening were purchased from the local market, Kafrelsheikh city, Egypt. All chemicals and solvents were used in this study were analytical grade and Sigma Company.

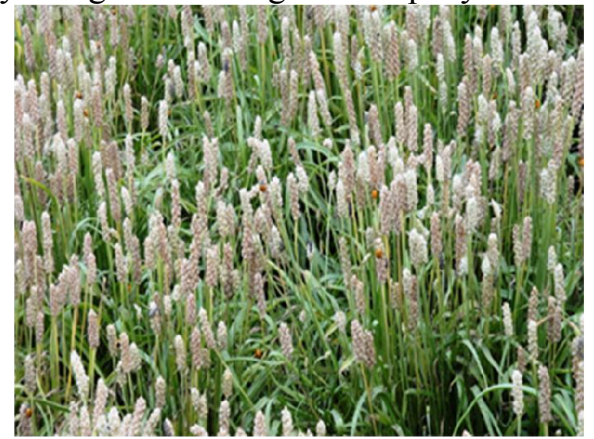

Plate 1: Psyllium plant (Plantago ovata).

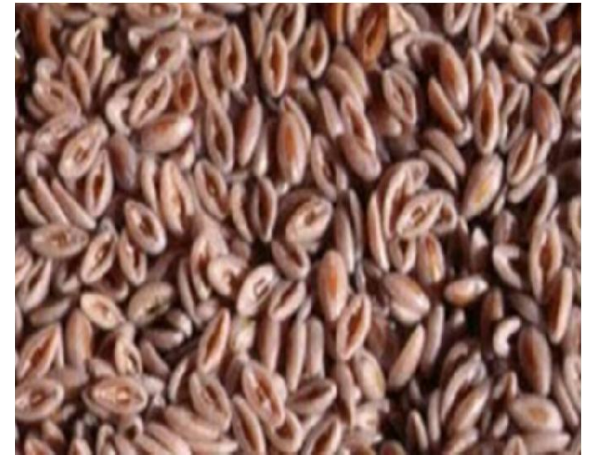

Plate 2: Psyllium seed 


\section{Methods}

\section{Pan bread processing:}

The straight dough process was performed in pan bread preparation according to the method described by Curie et al. (2002). The materials were: $100 \mathrm{~g} \mathrm{WF}, 1.5 \mathrm{~g}$ instant active dry yeast, $2.0 \mathrm{~g}$ salt, $2.0 \mathrm{~g}$ sugar, $3.0 \mathrm{~g}$ shortening and water (according to farinograph test). Formulas (0, 2, 3 and 4) containing PSF as partially substitute for WF at different extents $(0,5,10$ and $15 \%)$ were placed in a mixing bowl at $28 \pm 2.0^{\circ} \mathrm{C}$ and mixing for 6 min, after mixing, the formulated dough was rounded manually by folding for 20 times, then the bulk dough was leaved to rest for $10 \mathrm{~min}$. The prepared dough was placed in lightly greased a baking pan. The dough was proved for $80 \mathrm{~min}$ in a cabinet at 30 $\pm 0.5{ }^{\circ} \mathrm{C}$ and $85 \%$ relative humidity then baked for $20 \mathrm{~min}$ at $250{ }^{\circ} \mathrm{C}$ in an electrical oven. Before measurements, the baked pan bread was cooled at room temperature $\left(25 \pm 2.0^{\circ} \mathrm{C}\right)$ for $60 \mathrm{~min}$ and then packed in polyethylene bags. Pan bread formulation is shown in Table 1.

Table 1: Pan bread formulation.

\begin{tabular}{lcccc}
\hline Constituents & Control & Formula (1) & Formula(2) & Formula(3) \\
\hline WF (72\%) & 100 & 95 & 90 & 10 \\
PSF (\%) & 0 & 5 & 2 & 15 \\
Salt (g) & 2 & 2 & 1.5 & 2 \\
Yeast (g) & 1.5 & 1.5 & 2 & 1.5 \\
Sugar (g) & 2 & 2 & 3 & 3 \\
Shortening (g) & 3 & 3 & 3 \\
\hline
\end{tabular}

$\mathbf{P S F}=$ Psyllium seeds flour $\mathbf{W F}=$ Wheat flour $72 \%$ extraction

\section{Chemical analysis:}

Psyllium seed flour and pan bread blends were analyzed for crude protein, ash, crude ether extract and crude fiber according to the methods of AOAC (2005). Available carbohydrates were calculated by difference.

$$
\% \text { Available carbohydrates }=100-(\text { protein }+ \text { ash }+ \text { ether extract }+ \text { crude fiber })
$$

Calorie value were calculated agreeing to the Atwater system FAO (2000).

Calorie value $(\mathrm{kcal} / 100 \mathrm{~g})=(\%$ carbohydrate $\times 4.1)+(\%$ protein $\times 4.1)+(\%$ fat $\times 9.1)$.

\section{Determination of minerals:}

Minerals were analyzed according to the methods of AOAC (2005).

\section{Determination of soluble and insoluble dietary fiber:} (1983).

Soluble and insoluble fiber were determined according to the method described by ASP et al.,

\section{Determination of amino acids:}

Amino acids content of PSF and WF-PSF samples analyzed in National Research Center, Giza, Egypt, as follows: Samples were subjected to acid hydrolysis using 6N HCL. The hydrolyzate was recovered by removing the acid by evaporation in a rotary evaporator. The resulted amino acids were analyzed using amino acid analyzer (LC 3000 amino acid analyzer, High performance system, a product of LC biochrom Eppdrop, Germany). Flow rate $0.2 \mathrm{ml} / \mathrm{min}$, pressure of buffer from 0 to 2 bars, pressure of reagent to $0-150$ bar and reaction temperature $123{ }^{\circ} \mathrm{C}$. Amino acids were analyzed according to the method described in AOAC (2005).

\section{Computed protein efficiency ratio (C-PER):}

C-PER was calculated as described by Alsmeyer et al. (1974) following the equation: C-PER = $0.684+0.456$ (Leucine) -0.047 (proline).

\section{Computed Biological value (BV):}

Biological value was calculated as described by Farag, (1996) according following equation: Computed Biological Value $(\mathrm{BV})=49.9+10.53 \mathrm{C}-\mathrm{PER}$. 


\section{Rheological properties:}

Rheological properties of the different mixtures were estimated by Brabender Farinograph and Extensograph apparatus according to AACC (2012).

\section{Sensory evaluation of pan bread:}

Ten panelists from the staff of Sakha food Technology Research Laboratory., Agric. Res. Center. Egypt were asked for sensory evaluation of pan bread appearance, volume, crumb texture, crumb grain, crust color, taste, odor and overall acceptability according to the method described by Matz, (1972). Panelists evaluated pan bread formulas on a 10 point hedonic scale.

\section{Pan bread physical parameters:}

The average weight of loaves was recorded after cooling the loaves for $3 \mathrm{hrs}$. The loaf volume was measured by rapeseed displacement method as described by AACC (1983). Specific volume $\left(\mathrm{cm}^{3} / \mathrm{g}\right)$ was calculated by dividing volume of the loaf by its weight.

\section{Statistical Analysis:}

Statistical analysis was done using SPSS software (version 15) and Duncan's multiple range tests was used for mean comparison.

\section{Results and Discussion}

\section{Proximate composition of WF and PSF composite ( $\mathrm{g} / \mathrm{100} \mathrm{g}$ on dry weight basis)}

Table 2 studied the chemical composition of WF 72\% extraction and PSF on dry weight basis. WF $72 \%$ extraction and PSF were found to contain 11.81 and $16.40 \%$ for protein and 0.75 and $5.40 \%$ for crude ether extract and 0.45 and $3.70 \%$ for ash and 86.97 and $74.50 \%$ for total carbohydrates and 0.84 and $26.50 \%$ for crude fiber and 0.35 and $0.49 \%$ for soluble fiber and 0.49 and $20.50 \%$ for insoluble fiber and 398.5 and $306.20 \mathrm{Kcal} / 100 \mathrm{~g}$ for caloric value, respectively.

Table 2: Chemical composition of raw materials ( $\mathrm{g} / 100 \mathrm{~g}$ on dry weight basis).

\begin{tabular}{lcc}
\hline Raw materials & WF & PSF \\
\hline Crude protein \% & $11.81 \pm 0.11$ & $16.40 \pm 0.22$ \\
Crude ether extract \% & $0.75 \pm 0.06$ & $5.40 \pm 0.20$ \\
Ash \% & $0.45 \pm 0.05$ & $3.70 \pm 0.15$ \\
Total carbohydrates \% & $86.97 \pm 0.39$ & $74.50 \pm 0.55$ \\
Available carbohydrates \% & $86.13 \pm 0.40$ & $48.00 \pm 0.33$ \\
Crude fiber \% & $0.84 \pm 0.06$ & $26.50 \pm 0.66$ \\
Soluble fiber \% & $0.35 \pm 0.03$ & $6.00 \pm 0.06$ \\
Insoluble fiber \% & $0.49 \pm 0.05$ & $20.50 \pm 0.25$ \\
Caloric value (kcal/100g) & $398.51 \pm 0.88$ & $306.20 \pm 0.78$ \\
\hline
\end{tabular}

Each value was an average of three determinations \pm standard deviation.

$\mathbf{W F}=$ Wheat flour $\mathbf{P S F}=$ Psyllium seed flour

These results are nearly in agreement with Romero-Baranzini et al., (2006) who found that PSF contained $17.4 \%$ protein and $24.6 \%$ crude fiber. Ziemichód et al., (2018) revealed that Plantago ovata contain 15.45 crude protein, 3.55 fat. Khalil et al., (2002) reported that WF 72\% extraction comprised $11.38 \%$ crude protein, $0.82 \%$ fat, $0.45 \%$ ash and $86.79 \%$ total carbohydrates. Hafez, (2004) illustrated that WF $72 \%$ extraction contain $0.74 \%$ ether extract and $0.83 \%$ crude fiber. Plantago psyllium mucilage or Plantago psyllium ovata is a food grade polysaccharide. It has soluble fiber component. Psyllium has wide application in many health problems. Many researchers have investigated amazing health benefits of psyllium mucilage particularly cholesterol control, preparation for colonoscopy procedure, increasing absorption of water during ingestion subsequent to relaxed stools and reduced pain associated with hemorrhoids, colon cancer prevention, high sugar levels in blood, obesity and weight loss, inflammatory bowel disease, and widely used as laxative (Kumar et al., 2017). 


\section{Chemical composition of pan bread $(\mathrm{g} / 100 \mathrm{~g}$ on dry weight basis).}

Table 3 showed the comprise of the mean value of the chemical composition and caloric value of the produced pan bread substituted with $5 \%, 10 \%$ and $15 \%$ of PSF. The results explain crude protein, total fat, crude fiber and ash increased significant in pan bread substituted with PSF compared with control with out of PSF. This may be due to increased amount of crude fiber, total fat, crude fiber and ash in PSF. This clearly indicates that PSF can be an alternative source of dietary fiber in pan bread processing. This study is consistent with hose obtained by Krystyjan, (2018) found that biscuit prepared from psyllium seeds flour at different extent $(0,5,10$ and $20 \%$ of PSF) increased of crude ether extract, crude fiber and ash. Whereas, available carbohydrates and caloric value reduced.

Table 3: The chemical composition of pan bread ( $\mathrm{g} / 100 \mathrm{~g}$ on dry weight basis).

\begin{tabular}{lcccccc}
\hline Blends & $\begin{array}{c}\text { Crude } \\
\text { protein } \\
\mathbf{( \% )}\end{array}$ & $\begin{array}{c}\text { Ether } \\
\text { extract } \\
\mathbf{( \% )}\end{array}$ & $\begin{array}{c}\text { Ash } \\
\mathbf{( \% )}\end{array}$ & $\begin{array}{c}\text { Crude fiber } \\
\mathbf{( \% )}\end{array}$ & $\begin{array}{c}\text { Available } \\
\text { carbohydrates } \\
(\%)\end{array}$ & $\begin{array}{c}\text { Caloric } \\
\text { value } \\
(\mathbf{k c a l} / \mathbf{1 0 0 g})\end{array}$ \\
\hline \multirow{2}{*}{ Control } & $12.75^{\mathrm{d}}$ & $3.80^{\mathrm{d}}$ & $0.55^{\mathrm{d}}$ & $0.80^{\mathrm{d}}$ & $82.10^{\mathrm{a}}$ & $413.60^{\mathrm{a}}$ \\
& \pm 0.05 & \pm 0.02 & \pm 0.01 & \pm 0.02 & \pm 0.11 & \pm 0.10 \\
\hline \multirow{2}{*}{$\mathbf{5 \%} \mathbf{P S F}$} & $13.65^{\mathrm{c}}$ & $3.95^{\mathrm{c}}$ & $0.65^{\mathrm{c}}$ & $2.11^{\mathrm{c}}$ & $79.64^{\mathrm{b}}$ & $408.71^{\mathrm{b}}$ \\
& \pm 0.02 & \pm 0.03 & \pm 0.02 & \pm 0.01 & \pm 0.12 & \pm 0.10 \\
\hline \multirow{2}{*}{$\mathbf{1 0 \%} \mathbf{P S F}$} & $14.45^{\mathrm{b}}$ & $4.20^{\mathrm{b}}$ & $0.80^{\mathrm{b}}$ & $3.38^{\mathrm{b}}$ & $77.17^{\mathrm{c}}$ & $404.28^{\mathrm{c}}$ \\
& \pm 0.03 & \pm 0.05 & \pm 0.02 & \pm 0.03 & \pm 0.14 & \pm 0.12 \\
\hline \multirow{2}{*}{$\mathbf{1 5 \%}$ PSF } & $15.27^{\mathrm{a}}$ & $4.45^{\mathrm{a}}$ & $0.95^{\mathrm{a}}$ & $4.65^{\mathrm{a}}$ & $74.68^{\mathrm{d}}$ & $399.85^{\mathrm{d}}$ \\
& \pm 0.04 & \pm 0.01 & \pm 0.01 & \pm 0.05 & \pm 0.15 & \pm 0.13 \\
\hline
\end{tabular}

Means with different letter in the same column are significantly different at LSD at $(p \leq 0.05)$.

Each value was an average of three determinations \pm standard deviation.

PSF: Psyllium seed flour.

\section{Mineral contents of PSF, WF pan bread and WF- PSF composite pan bread (mg/100g on dry weight basis).}

The data in Table 4 indicated that content of macro and micro mineral elements of control pan bread without PSF and pan bread enriched with PSF. It is clear from the table that pan bread enriched with PSF was increased the content of calcium $(\mathrm{Ca})$, sodium $(\mathrm{Na})$, phosphorus $(\mathrm{P})$, potassium $(\mathrm{K})$, manganese $(\mathrm{Mn})$ and iron compare with control of pan bread prepared from WF.

Table 4: Mineral contents of PSF, WF pan bread and WF-PSF composite pan bread (mg/100g on dry weight basis).

\begin{tabular}{lcccccccc}
\hline \multirow{2}{*}{ Mineral } & $\begin{array}{c}\mathbf{C a} \\
\mathbf{( m g} /\end{array}$ & $\begin{array}{c}\mathbf{N a} \\
\mathbf{( m g /}\end{array}$ & $\begin{array}{c}\mathbf{P} \\
\mathbf{( m g} /\end{array}$ & $\begin{array}{c}\mathbf{K} \\
\mathbf{( m g} /\end{array}$ & $\begin{array}{c}\mathbf{M g} \\
\mathbf{( m g} /\end{array}$ & $\begin{array}{c}\mathbf{F e} \\
\mathbf{( m g} /\end{array}$ & $\begin{array}{c}\mathbf{M n} \\
\mathbf{( m g /}\end{array}$ & $\begin{array}{c}\mathbf{Z n} \\
\mathbf{( m g /}\end{array}$ \\
& $\mathbf{1 0 0 g})$ & $\mathbf{1 0 0 g})$ & $\mathbf{1 0 0 g})$ & $\mathbf{1 0 0 g})$ & $\mathbf{1 0 0 g})$ & $\mathbf{1 0 0 g})$ & $\mathbf{1 0 0 g})$ & $\mathbf{1 0 0 g})$ \\
\hline \multirow{2}{*}{ PSF } & 160.05 & 33.54 & 650.33 & 750.11 & 99.22 & 16.30 & 2.50 & 3.50 \\
& \pm 0.34 & \pm 1.50 & \pm 1.22 & \pm 1.80 & \pm 2.50 & \pm 0.04 & \pm 0.01 & \pm 0.02 \\
\hline \multirow{2}{*}{ Control } & 17.03 & 4.95 & 132.50 & 150.00 & 107.55 & 1.90 & 0.82 & 4.30 \\
& \pm 0.45 & \pm 0.05 & \pm 1.24 & \pm 0.65 & \pm 0.44 & \pm 0.03 & \pm .02 & \pm 0.07 \\
\hline \multirow{2}{*}{$\mathbf{0 5 \%}$ PSF } & 23.58 & 6.40 & 156.80 & 176.40 & 107.15 & 2.45 & 0.89 & 4.17 \\
& \pm 0.23 & \pm 0.30 & \pm 1.33 & \pm 0.88 & \pm 0.55 & \pm 0.02 & \pm 0.03 & \pm 0.11 \\
\hline \multirow{2}{*}{$\mathbf{1 0 \%}$ PSF } & 30.77 & 7.82 & 182.77 & 206.60 & 106.75 & 3.18 & 0.97 & 4.13 \\
& \pm 0.24 & \pm 0.40 & \pm 1.60 & \pm 1.70 & \pm 0.65 & \pm 0.03 & \pm 0.01 & \pm 0.02 \\
\hline \multirow{2}{*}{$\mathbf{1 5 \%}$ PSF } & 38.20 & 9.25 & 208.75 & 236.80 & 106.32 & 3.92 & 1.05 & 4.09 \\
& \pm 0.23 & \pm 0.66 & \pm 1.55 & \pm 1.90 & \pm 1.33 & \pm 0.06 & \pm 0.01 & \pm 0.05
\end{tabular}

Each value was an average of three determinations \pm standard deviation.

PSF: Psyllium seed flour.

The data show a decrease in element of magnesium $(\mathrm{Mg})$ and zinc $(\mathrm{Zn})$ for pan bread enriched with PSF compared with control of pan bread. It is clear from the results that the pan bread content of mineral elements depends content of PSF. The PSF are comparatively source of indispensable minerals. Ziemichód et al., (2018) demonstrated that psyllium seeds contain $\mathrm{Na}, \mathrm{Ca}, \mathrm{K}, \mathrm{Fe}, \mathrm{Mn}$ and $\mathrm{Zn}$ were $331,1440,7380,183,12.2$ and $27.4 \mathrm{mg} / \mathrm{kg}$, respectively. 


\section{The $\mathrm{Na} / \mathrm{k}$ ratio of PSF, WF and WF-PSF pan bread:}

Fig. 1 clear $\mathrm{Na} / \mathrm{K}$ ratio and pan bread without of PSF or pan bread made from different level of PSF. $\mathrm{Na} / \mathrm{K}$ ratio of PSF was high in comparative with pan bread without of PSF or pan bread made from different level of PSF.

The $\mathrm{Na} / \mathrm{K}$ ratio less than one with increasing the levels of substitution $(5 \%, 10 \%$ and $15 \%)$ of PSF pan bread. Aremu et al. (2006) illustrated that $\mathrm{Na} / \mathrm{K}$ ratio less than one have a great importance in the body for the control of high blood pressure

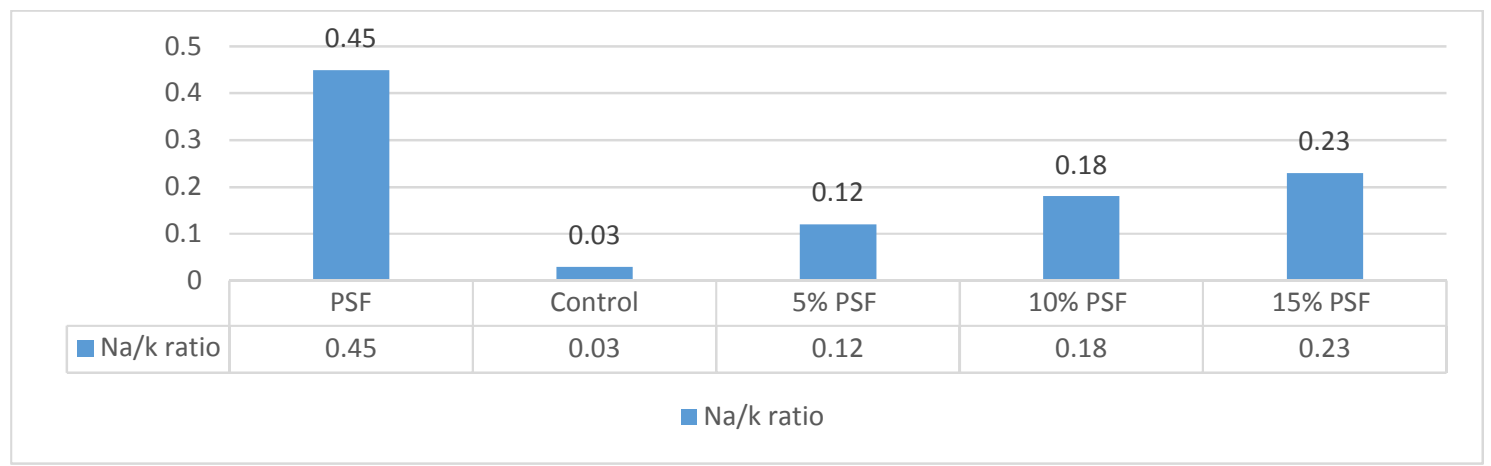

Fig. 1: Na/k ratio of PSF, WF and WF-PSF pan bread.

\section{Amino acids profile of PSF and pan bread made from WF-PSF ( $\mathrm{g} / 100 \mathrm{~g}$ of protein):}

Data given in Table 5 presented the amino acid composition ( $\mathrm{g}$ amino acid $/ 100 \mathrm{~g}$ protein.) of PSF, pan bread preparation of WF 72\% extraction and different levels of WF-PSF of pan bread. The obtained results indicated that, the amount of total indispensable amino acids of pan bread formulas contained (5\% PSF, $10 \%$ PSF and $15 \% \mathrm{PSF}$ ) were relatively higher compared to pan bread prepared from wheat flour ( $72 \%$ extraction). On the other hand, total non-essential amino acids contents were lower in formulas prepared with WF-PSF pan bread compared to control prepared from wheat flour $72 \%$ extraction. Computed protein efficiency ratio C- PER and biological value BV of PSF, pan bread made from WF and pan bread made from WF- PSF were presented in Table 5. The results in this Table showed that the (C-PER and BV) were higher in formulas prepared with $(5 \%, 10 \%$ and $15 \%$ SPF) than those of control WF.

Romero-Baranzini et al. (2006) found that PSF surpassed the requirement of indispensable amino acids and seems to be a good source of lysine and methionine $(6.82$ and $2.61 \mathrm{~g} / 100 \mathrm{~g}$ of protein, respectively). These values are higher than that reported for a plantago ovata cultivar from India with 4.14 and $1.7 \mathrm{~g} / 100 \mathrm{~g}$ of protein for lysine and methionine, respectively (Chakrabortty and Patel, 1992). Genotypic and environmental variances could reason for the observed variances.

\section{Some amino acids ratio of PSF, control, 5\%PSF, $10 \% \mathrm{PSF}$ and $15 \%$ PSF of pan bread as compared with casein:}

Table 6 show some amino acids ratio of PSF, control, 5, 10 and $15 \%$ of PSF pan bread as compared with casein. Methionine: glycine ratios were $0.40,0.33,0.34,0.34,0.34$ and 1.72 for PSF, control, 5, 10 and $15 \%$ of PSF pan bread and casein, respectively. Also, lysine: arginine ratios were $0.77,0.1 .12,1.02,0.95,0.92$ and 1.78 for $\mathrm{f} \mathrm{PSF}$, control, 5,10 and $15 \%$ of PSF pan bread and casein. On the other hand, leucine: isoleucine ratios were 1.61, 1.05, 1.07, 1.10, 1.14 and 1.04 for PSF, control 5, 10 and $15 \%$ of PSF pan bread and casein, respectively.

Methionine: glycine ratios and lysine: arginine ratios of casein was high in comparative with raw materials amino acids, led to hypocholesterolemic ratio in serum of blood. On the contrary, leucine: isoleucine ratio of raw materials was high compare with casein. Also, a significant strong positive correlation with serum cholesterol concentration was observed (El Hadidy, 2014). 
Table 5: Amino acids profile of PSF and pan bread made from WF-PSF ( $\mathrm{g} / \mathrm{100 \textrm {g }}$ of protein)

\begin{tabular}{|c|c|c|c|c|c|}
\hline Amino acids & PSF & Control & $5 \%$ PSF & $10 \%$ PSF & $15 \%$ PSF \\
\hline \multicolumn{6}{|c|}{ Essential amino acids } \\
\hline Lysine & 6.33 & 2.60 & 2.76 & 2.95 & 3.15 \\
\hline Isoleucine & 5.02 & 4.03 & 4.15 & 4.20 & 4.25 \\
\hline Leucine & 8.10 & 4.25 & 4.45 & 4.63 & 4.83 \\
\hline Phenyl alanine & 4.18 & 5.26 & 5.20 & 5.15 & 5.10 \\
\hline Tyrosine & 6.20 & 1.90 & 2.05 & 2.30 & 2.50 \\
\hline Histidine & 3.50 & 4.00 & 3.98 & 3.95 & 3.93 \\
\hline Valine & 5.80 & 4.40 & 4.45 & 4.55 & 4.60 \\
\hline Theronine & 4.90 & 2.00 & 2.10 & 2.25 & 2.45 \\
\hline Methionine & 2.21 & 1.20 & 1.30 & 1.35 & 1.40 \\
\hline Total (EAA) & 46.24 & 29.64 & 30.44 & 31.33 & 31.21 \\
\hline \multicolumn{6}{|c|}{ Non-essential amino acids } \\
\hline Aspartic & 7.55 & 5.50 & 5.55 & 5.65 & 5.75 \\
\hline Glutamic & 13.00 & 32.55 & 31.10 & 31.10 & 30.09 \\
\hline Proline & 7.60 & 12.80 & 12.50 & 12.20 & 11.90 \\
\hline Serine & 5.10 & 6.80 & 6.70 & 6.60 & 6.45 \\
\hline Glycine & 5.55 & 3.60 & 3.85 & 4.00 & 4.15 \\
\hline Alanine & 6.12 & 3.80 & 3.75 & 3.88 & 4.00 \\
\hline Arginine & 8.20 & 2.33 & 2.70 & 3.10 & 3.42 \\
\hline Total (NEAA) & 53.12 & 67.38 & 66.15 & 66.53 & 65.76 \\
\hline C-PER & 4.04 & 2.03 & 2.13 & 2.22 & 2.33 \\
\hline BV & 92.23 & 71.27 & 72.28 & 73.30 & 74.41 \\
\hline
\end{tabular}

Table 6: Some amino acids ratio of PSF, control, 5\%PSF, $10 \% \mathrm{PSF}$ and $15 \% \mathrm{PSF}$ of pan bread as compared with casein.

\begin{tabular}{lcccccc}
\hline Ratio & PSF & Control & 5\% PSF & $\mathbf{1 0 \%}$ PSF & $\mathbf{1 5 \%}$ PSF & Casein \\
\hline Methionine : Glycine & 0.40 & 0.33 & 0.34 & 0.34 & 0.34 & 1.72 \\
Lysine: Arginine & 0.77 & 1.12 & 1.02 & 0.95 & 0.92 & 1.78 \\
Leucine: Isoleucine & 1.61 & 1.05 & 1.07 & 1.10 & 1.14 & 1.04 \\
\hline
\end{tabular}

\section{Farinograph test:}

Results in Table 7 explain the rheological characterize estimated by farinograph apparatus for four formulas using wheat flour without or with PSF. From these results it could be noticed that addition of PSF to WF lead to increase the water absorption (\%), arrival time(min), development dough(min), stability(min). On the other hand, degree of softening (B. U) was decreased with added of PSF. The high capacity of water absorption of psyllium husk is due to the molecular structure of Psyllium Seed, $75 \%$ xylose, $23 \%$ arabinose, traces of other sugar, and almost $35 \%$ of non-reducing terminal remains (Fischer et al., 2004). The influences of oat bran and wheat bran as sources high concentrations of soluble and insoluble fiber in the formulation of instant vermicelli, in addition to its influence on the rheological properties and product quality. The addition of oat bran and wheat bran from $(0$ to $20 \%$ ) in the blends raised the water absorption significantly from 58.3 to $64.1 \%$ (Sudha et al., 2011). The variances in water absorption is principally caused by numerous hydroxyl groups existing in the fibers and let more water interaction throughout hydrogen bonding (Rosell et al., 2001).

\section{Extensograph test:}

The results presented in Table 8 clarify the effect of adding 5, 10 and $15 \%$ of PSF to WF on the extensograph parameters. From these results it could be noticed that addition of PSF to WF lead to increase the elasticity (B.U), proportional number and energy $\left(\mathrm{cm}^{2}\right)$ compare with control dough. On the contrary, extensibility (min) of formulas of pan bread enriched with PSF was reduced. Energy was increased by addition PSF at levels of 5 and $10 \%$ of PSF were $\left(62\right.$ and $\left.76 \mathrm{~cm}^{2}\right)$, respectively. Also, proportional number increased in all formulas enriched with PSF. 
Table 7: Farinograph parameters WF and WF-PSF dough.

\begin{tabular}{cccccc}
\hline Samples & $\begin{array}{c}\text { Water } \\
\text { absorption } \\
(\mathbf{\%})\end{array}$ & $\begin{array}{c}\text { Arrival } \\
\text { time } \\
(\mathbf{m i n})\end{array}$ & $\begin{array}{c}\text { development } \\
\text { Dough } \\
(\mathbf{m i n})\end{array}$ & $\begin{array}{c}\text { Stability } \\
(\mathbf{m i n})\end{array}$ & $\begin{array}{c}\text { Degree of } \\
\text { softening } \\
\text { (B.U) }\end{array}$ \\
\hline \multirow{2}{*}{ Control } & 59.2 & 0.5 & 1.0 & 10 & 40 \\
& \pm 0.50 & \pm 0.05 & \pm 0.03 & \pm 0.22 & \pm 0.40 \\
\hline \multirow{2}{*}{$\mathbf{5} \% \mathbf{P S F}$} & 62.7 & 1.0 & 2.5 & 12.50 & 30 \\
& \pm 0.55 & \pm 0.03 & \pm 0.04 & \pm 0.20 & \pm 0.30 \\
\hline \multirow{2}{*}{$\mathbf{1 0} \% \mathbf{P S F}$} & 65.3 & 1.5 & 3.5 & 16.00 & 20 \\
& \pm 0.60 & \pm 0.02 & \pm 0.05 & \pm 0.15 & \pm 0.25 \\
\hline \multirow{2}{*}{$\mathbf{1 5} \% \mathbf{P S F}$} & 68.6 & 2.0 & 4.5 & 18.50 & 20 \\
& \pm 0.45 & \pm 0.01 & \pm 0.06 & \pm 0.25 & \pm 0.32 \\
\hline
\end{tabular}

Each value was an average of three determinations \pm standard deviation.

PSF: Psyllium seed flour.

Table 8: Extensograph parameters of WF and WF-PSF dough.

\begin{tabular}{ccccc}
\hline Dough properties & $\begin{array}{c}\text { Elasticity } \\
(\mathbf{B . U})\end{array}$ & $\begin{array}{c}\text { Extensibility } \\
(\mathbf{m i n})\end{array}$ & $\begin{array}{c}\text { Proportional } \\
\text { number }\end{array}$ & $\begin{array}{c}\text { Energy } \\
\left(\mathbf{c m}^{2}\right)\end{array}$ \\
\hline \multirow{2}{*}{ Control } & 220 & 130 & 1.69 & 47 \\
& \pm 2.33 & \pm 0.35 & \pm 0.03 & \pm 0.65 \\
\hline \multirow{2}{*}{$\mathbf{5 \%}$ PSF } & 440 & 80 & 5.50 & 62 \\
& \pm 3.50 & \pm 0.80 & \pm 0.02 & \pm 0.65 \\
\hline \multirow{2}{*}{$\mathbf{1 0} \% \mathbf{P S F}$} & 600 & 75 & 8.00 & 76 \\
& \pm 4.70 & \pm 0.65 & \pm 0.04 & \pm 0.70 \\
\hline \multirow{2}{*}{$\mathbf{1 5 \%}$ PSF } & 720 & 50 & 14.40 & 51 \\
& \pm 3.50 & \pm 0.65 & \pm 0.08 & \pm 0.80 \\
\hline
\end{tabular}

Each value was an average of three determinations \pm standard deviation.

PSF: Psyllium seed flour.

\section{Sensory evaluation of pan bread:}

Results of sensory parameters such as appearance, volume, crumb texture, crumb grain, crust color, taste, odor and overall acceptability are presented in Table 9 and Fig.2. It could be observed that all the formulas were significant decrease in appearance, volume, crumb texture, crumb grain, crust color, taste, odor and overall acceptability. Pan bread produced by partial substitution of wheat flour with PSF at extent 5, 10 and $15 \%$ characterized with good sensorial properties. It seems, that the decrease in pan bread volume resulting from increased level of the PSF or fiber addition is most likely due to the combined effects of gluten dilution and mechanical disruption of the gluten network structure by the SPF particles. The comparatively stable water activity in pan bread crumb, in spite of the increase in water content from incorporating hydrate PSF, due to enhance pan bread softness without significantly increasing the hazard microbial deteriorate (Czuchajowska et al., 1992).

The differences in the color of pan bread enriched with PSF resulted from two reasons. The first and dominant was the color of the PSF, which was characterized by a greyish shade and strongly affected the overall color of the dough and breads. This was also noticed by the panelists. On the contrary, when comparing the chemical composition of WF and PSF it was indicated that the WF was characterized by a higher protein content, which had a significant influence on the Maillard reaction during baking. The increased amount of mucilage of PSF reduced swelling of gluten in the WF-PSF biscuits and due to limited of volume according to Krystyjan et al. (2018). The results showed that sensorial parameters, at 5,10 and $15 \%$ of the PSF addition to the pan bread the quality parameters of the pan bread significantly deteriorated at $15 \%$ portion of wheat flour, the color deteriorated (was too greyish in panelists opinion), it seems that 5, 10 and $15 \%$ PSF fortification of pan bread is suitable to obese patients. 

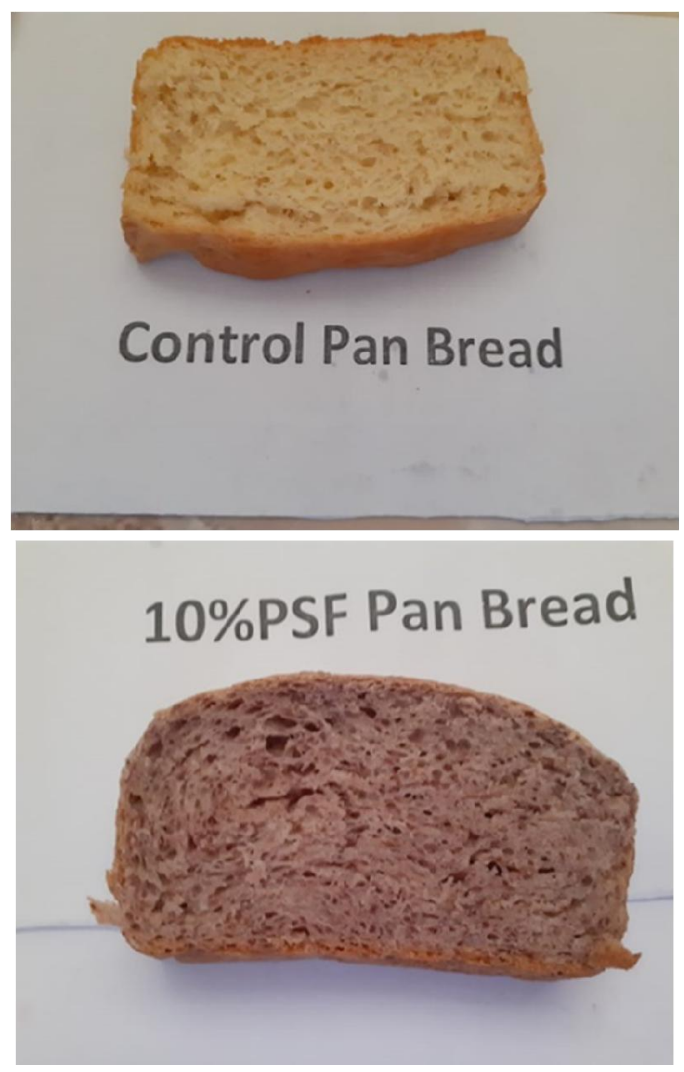

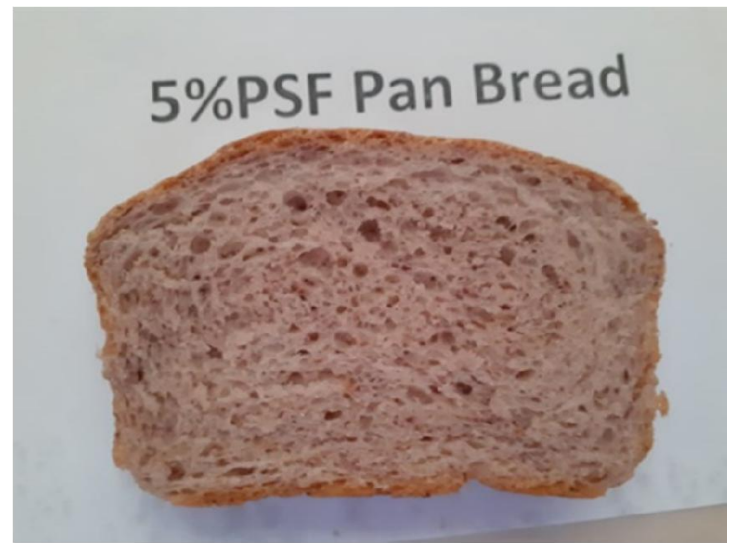

\section{5\%PSF Pan Bread}

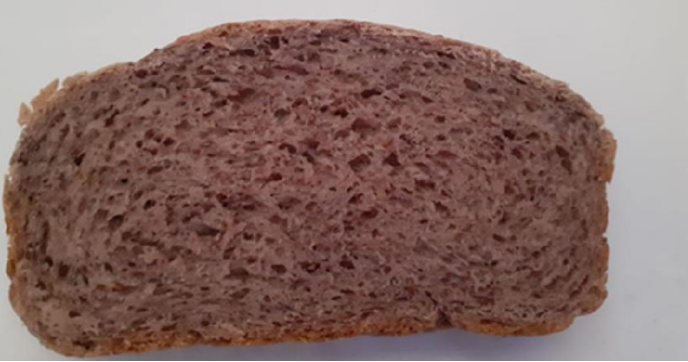

Fig. 2: Pan bread formulas enriched with PSF.

Table 9: Sensory evaluation of pan bread fortified with PSF.

\begin{tabular}{|c|c|c|c|c|c|c|c|c|}
\hline Blends & $\begin{array}{c}\text { Appearance } \\
10\end{array}$ & $\begin{array}{c}\text { Volume } \\
10\end{array}$ & $\begin{array}{c}\text { Crumb } \\
\text { texture } \\
10\end{array}$ & $\begin{array}{c}\text { Crumb } \\
\text { grain } \\
10\end{array}$ & $\begin{array}{c}\text { Crust } \\
\text { color } \\
10 \\
\end{array}$ & $\begin{array}{c}\text { Taste } \\
10\end{array}$ & $\begin{array}{c}\text { Odor } \\
10\end{array}$ & $\begin{array}{c}\text { Overall } \\
\text { Acceptability } \\
10\end{array}$ \\
\hline \multirow[b]{2}{*}{ Control } & $9.70^{\mathrm{a}}$ & $9.75^{\mathrm{a}}$ & $9.50^{\mathrm{a}}$ & $9.30^{\mathrm{a}}$ & $9.40^{\mathrm{a}}$ & $9.20^{\mathrm{a}}$ & $9.20^{\mathrm{a}}$ & $9.20^{\mathrm{a}}$ \\
\hline & \pm 0.52 & \pm 0.22 & \pm 0.32 & \pm 0.46 & \pm 0.22 & \pm 0.22 & \pm 0.32 & \pm 0.44 \\
\hline \multirow{2}{*}{$5 \%$ PSF } & $8.80^{b}$ & $8.50^{b}$ & $9.00^{\mathrm{ab}}$ & $8.80^{\mathrm{b}}$ & $8.30^{\mathrm{b}}$ & $8.50^{b}$ & $8.80^{\mathrm{ab}}$ & $8.00^{b}$ \\
\hline & \pm 0.48 & \pm 0.50 & \pm 0.59 & \pm 0.74 & \pm 0.50 & \pm 1.70 & \pm 1.11 & \pm 0.40 \\
\hline \multirow{2}{*}{$10 \%$ PSF } & $8.20^{\mathrm{bc}}$ & $7.80^{\mathrm{c}}$ & $8.80^{\mathrm{b}}$ & $8.50^{b}$ & $8.10^{\mathrm{b}}$ & $8.00^{\mathrm{d}}$ & $8.30^{\mathrm{bc}}$ & $7.50^{\mathrm{b}}$ \\
\hline & \pm 0.41 & \pm 0.28 & \pm 0.86 & \pm 1.70 & \pm 0.59 & \pm 0.48 & \pm 1.77 & \pm 0.36 \\
\hline \multirow{2}{*}{$15 \%$ PSF } & $7.50^{\mathrm{c}}$ & $7.30^{\mathrm{d}}$ & $8.50^{b}$ & $7.60^{\mathrm{c}}$ & $6.70^{c}$ & $7.20^{\mathrm{d}}$ & $7.80^{\mathrm{c}}$ & $6.70^{c}$ \\
\hline & \pm 0.42 & \pm 1.69 & \pm 1.70 & \pm 1.11 & \pm 1.70 & \pm 1.77 & \pm 1.60 & \pm 1.77 \\
\hline
\end{tabular}

Means with different letter in the same column are significantly different at LSD at $(p \leq 0.05)$.

Each value was an average of ten determinations \pm standard deviation.

PSF: Psyllium seed flour.

\section{Physical properties of fortified pan bread:}

The impact of pan bread fortification with PSF on weight $(\mathrm{g})$, volume $\left(\mathrm{cm}^{3}\right)$ and specific volume $\left(\mathrm{cm}^{3} / \mathrm{g}\right)$ are presented in Table 10. From the results, it is revealed that pan bread enriched with PSF had lower values in volume and specific volume compare control pan bread. On the contrary, weight increased with increasing PSF ratio. These results are in agreement with Man et al., (2017) who explained that the volume of the bread reduced as the extent of PSF increased, the volume due to interactions among dietary fiber components, gluten and water. The increased amount of mucilage of PSF reduced swelling of gluten in the WF-PSF biscuits and due to limited of volume according to Krystyjan et al. (2018). 
Table 10: Influence of enriched wheat flour with PSF on the physical parameters of pan bread.

\begin{tabular}{|c|c|c|c|}
\hline Samples & $\begin{array}{c}\text { Volume } \\
\left(\mathrm{cm}^{3}\right)\end{array}$ & $\begin{array}{l}\text { Weight } \\
\text { (g) }\end{array}$ & $\begin{array}{l}\text { Specific volume } \\
\left(\mathrm{cm}^{3} / \mathrm{g}\right)\end{array}$ \\
\hline \multirow[b]{2}{*}{ Control } & 1375 & 460 & 2.98 \\
\hline & \pm 4.45 & \pm 02.40 & \pm 0.02 \\
\hline \multirow{2}{*}{$5 \%$ PSF } & 1325 & 510 & 2.60 \\
\hline & \pm 6.33 & \pm 2.20 & \pm 0.42 \\
\hline \multirow[b]{2}{*}{$10 \%$ PSF } & 1164 & 535 & 2.18 \\
\hline & \pm 5.20 & \pm 2.70 & \pm 0.03 \\
\hline $15 \%$ PSF & $\begin{array}{r}1011 \\
\pm 7.30 \\
\end{array}$ & $\begin{array}{c}560 \\
\pm 2.55 \\
\end{array}$ & $\begin{array}{c}1.81 \\
\pm 0.05 \\
\end{array}$ \\
\hline
\end{tabular}

Each value was an average of three determinations \pm standard deviation.

PSF: Psyllium seed flour.

\section{Conclusion}

From the overall results, it could be concluded that the partial substitution of wheat flour with psyllium seeds flour was modified the rheological properties of the dough to different extent. Inclusion of PSF in pan bread formula; increase its nutritional value, with only a small depreciation in pan bread quality. Organoleptic properties shown that the loaf supplemented up to15\% PSF was acceptable and has significant difference with control in terms of appearance, crumb texture, crumb grain, crust color, taste, odor and overall acceptability. Regardless to this, it could prepare some bakery products using PSF and WF flours with high quality that are suitable for obese patients.

\section{Acknowledgments:}

The authors thank Prof. Dr. Manal, Fahmy. A., for making pan bread formulas and providing language corrections.

\section{References}

AACC, 1983. Approved method of the American Association of Cereal Chemists Published by American Association of Cereal Chemists Inc. St. Paul, Minnesota, U.S.A.

AACC, 2012. International Methods approved of the American Association of Cereal Chemists, $11^{\text {th }}$ ed., American Association of Cereal Chemists, INC., St. Paul, Minnesota, USA.

Alsmeyer, R. H., A.E. Cuningham, and M.L. Happich, 1974. Equations predict PER from amino acid analysis. Food Tech., 28 (7): 34-40.

Alu'datt, M.T., K. Ereifej, I. Alli, M. Alrababah, A. Almajwal, N. Masadeh and M. Alhamad, 2012. Effects of barley flour and barley protein isolate on chemical, functional, nutritional and biological properties of pita bread. Food Hydrocolloids, 26: 135-143.

AOAC, 2005. Official Methods of Analysis of the Association of Official Analytical Chemists. $18^{\text {th }}$ edition, Washington DC.

Aremu, M.O., O. Olaofe and T.E. Akintayo, 2006. Comparative Study on the Chemical and Amino Acid Composition of Some Nigerian Under-Utilized Legume Flours. Pakistan Journal of Nutrition, 5: 34-38.

Ashwini, R.M., R.P. Monica and W. Deepa, 2014. Characterization of Psyllium (Plantago ovata) Polysaccharide and Its Uses. Springer International Publishing Switzerland, Pp: 1-17.

ASP, N.G., G.G. Johansson, H. Haller and M. Siljestrom, 1983. Rapid enzymatic assay of insoluble and dietary fiber. Journal of Agricultural and Food Chemistry, 31: 476-482.

Beara, I.N., M.M. Lesjak, E.D. Jovin, K.J. Balog, G.T. Anackov and D.Z. Orcicì, 2009. Plantain (Plantago L.) species as novel sources of flavonoid antioxidants. J. Agri. Food Chem., 57:9268-9273. doi:10.1021/jf902205m

Bedard, A.M., G.H. Lai, R.D. Wullschleger and J.G. Kincaid, 1995. Psyllium enriched pasta products and methods for making same. US Patent 5384144.

Chakrabortty, M.K. and K.V. Patel, 1992. Chemical composition of isabgol (Plantago ovata Forsk) seed. J. Food Sci. Technol., 29:389-390. 
Curie, D., J. Dugum, and I. Bauman, 2002. The influence of fungal amylase supplementation on amylolytic activity and baking quality of flour. International J. Food Sci. and Technology, 37: 673-680.

Czuchajowska, A., B. Paszczynska and Y. Pomeranz, 1992. Functional properties of psyllium in Wheat-Based products. J. Cereal Chemistry, 69(5):516-520.

El Hadidy, G.S., 2014. Chemical, technological and biological studies on mulberry leaves and purslane in Egypt. Ph.D. Thesis, Fac. Agric. Food Technology Dep., Mansoura Univ., Egypt.

El Sheikh, Dalia. M., 2014. Rheological characteristics of Arabic gum suspension and Plantago seeds mucilage, Journal of American Science, 10 (11):18-24.

FAO, 2002. Food energy. Methods of analysis and conversion factors. Food and Nutrition Paper 77. Report of a technical workshop, Rome 3-6 December. ISSN 0254-4725.

Farag, S.A., A. El-Shirbeeny and A.E. Nassef, 1996. Physicochemical studies for preparing quickcooking rice by using gamma irradiation. Annals of Agric Sci., Moshtohor, 34: 641-652.

Fischer. H., N. Yu, G.R. Gray, J. Ralph, L. Anderson, and J.A. Marletta, 2004. The gel forming polysaccharide of psyllium husk (Plantago ovata Forsk). Carbohydrate Research, 339: 20092017.

Guo, Q., S.W. Cui, Q. Wang and J.C. Young, 2008. Fractionation and physicochemical characterization of psyllium gum. Carbohyd. Polym., 73: 35-43.

Hafez, Hoda, H.A., 2004. Production and evaluation of some bakery products supplemented with soybean products. MSc. Thesis Food Sci. and Technol., Dept., Faculty of Agric., Cairo Univ., Egypt.

Huang, X.F. and J.Z. Chen, 2009. Obesity, the PI3K/Akt signal pathway and colon cancer, Obesity Reviews, 10, (6): 610-61.

Jat, R.S., R.N. Reddy, R. Bansal and P. Manivel, 2015. Good agriculture practices, for Isbagol. ICAR Direct orated of Medicinal and Aromatic Plants Research. Gujarat -India.

Khalil, Mona, M., M.A. Hussein, M.T. Salaby and J.A. Ghonim, 2002. Nutritional and biological evaluation of high nutritive biscuits processed for primary school children. Proceeding of the First Arab Mansoura Conf. of Dairy Sci. and Technol., J. Agric. Sci., 131-142.

Koletta, P., M. Irakli, M. Papageorgiou, and A. Skendi, 2014. Physicochemical and technological properties of highly enriched wheat breads with wholegrain non wheat flours. J Cereal Sci., 60(3):561-568.

Krystyjan, M., D. Gumul, A. Korus, J. Korus and M. Sikora, 2018. Physicochemical properties and sensory acceptance of biscuits fortified with Plantago psyllium flour. Emirates Journal of Food and Agriculture, 30(9): 758-763.

Kumar, D., J. Pandey, P. Kumar, and V. Raj, 2017. Psyllium Mucilage and Its Use in Pharmaceutical Field: An Overview, J. Curr. Synthetic Sys Biol., 5(1):1-7.

Man, S., A. Paucean, S. Muste, P.O.P. Anamaria and E.A. Muresan, 2017. Influence of psyllium husk (Plantago ovata) on bread quality. Bulletin UASVM Food Science and Technology, 74(1):33-34.

Matz, S. A., 1972. Bakery Technology and Engineering. The AVI Pub. Co., Westport, Connecticut.

Newman, C.W. and R.K. Newman, 2006. A brief history of barley foods. Cereal Foods World, 51:47.

Olivier, S.D., 2000. The long-term safety and tolerability of ispaghula husk. The Journal of the Royal Society for the Promotion of Health, 120:107-111.

Pawar, H., and C. Varkhade, 2014. Isolation, characterization and investigation of Plantago ovata husk polysaccharide as super disinter grant. International Journal of Biological Macromolecules, 69:52-58.

Roberfroid, M.B., 2000. A European consensus of scientific concepts of functional foods," Nutrition, 16, (7-8): 689-691.

Romero-Baranzini, A.L., O.G. Rodriguez, G.A. Yanez-Faries, J.M. Barron-Hoyos, and P. RayasDuarte, 2006. Chemical, Physicochemical, and Nutritional go (Plantago ovata Forsk). J Cereal Chem., 83(4):358-362.

Rosell, C. M., J.A. Rojas and C. Benedito de Barber, 2001. Influence of hydrocolloids on dough rheology and bread quality. Food Hydrocolloids, 15: 75-81. 
Samuelsen, A.B., 2000. The traditional uses, chemical constituents and biological activities of Plantago major L. A review. J. Ethno pharmacol. 71, 1-21. doi: 10.1016/S03788741(00)00212-9.

Singh, B., 2007. Psyllium as therapeutic and drug delivery agent. Int J Pharm., 334(1-2):1-14.

Sivam, A. S., D. Sun-Waterhouse, Y.Q. Siew and C.O. Perera, 2010. Properties of bread dough with added fiber polysaccharides and phenolic antioxidants: A review. Journal of Food Science, 75, (8): 163-174.

Sudha, M. L., G. Rajeswari and G. Venkateswara Rao, 2011. Effect of wheat and oat brans on the dough rheological and quality characteristics of instant vermicelli. Journal of Texture Studies doi: 10.1111/j.1745-4603.2011. 00329.x, 1-8.

Sukhija, S., S. Singh and C.S. Riar, 2016. Analyzing the effect of whey protein concentrate and psyllium husk on various characteristics of biodegradable film from lotus (Nelumbo nucifera) rhizome starch. Food Hydrocolloids, 60: 128-137.

Ziai, S. A., B. Larijani, S. Akhoondzadeh, H. Fakhrzadeh, A. Dastpak, F. Bandarian, A. Rezai, H.N. Badi and T. Emami, 2005. Psyllium decreased serum glucose and glycosylated hemoglobin significantly in diabetic outpatients. J. Ethnopharmacol., 102: 202-207.

Ziemichód, A., M. Wójcik and R. Rózyło, 2018. Seeds of Plantago psyllium and Plantago ovata: Mineral composition, grinding, and use for gluten-free bread as substitutes for hydrocolloids. J Food Process Eng., 1-9. 